\title{
CAUDOCRANIAL CONDUCTION IN THE LEFT AURICLE IN NODAL RHYTHM AND IN NODAL ECTOPIC BEATS
}

\author{
BY \\ R. WENGER \\ From the First Medical University Clinic, Vienna \\ Received October 21, 1953
}

As we described elsewhere (Wenger et al., 1950 and 1952) the pattern of œsophageal leads, as registered at various heights above the diaphragm, gives us the chance of drawing conclusions about the conduction in the left auricle. Esophageal $\mathbf{P}$ waves at auricular levels contain well defined intrinsicoid deflections (Brown, 1936; Neuman, 1951; Schwartz, 1947; Wenger, 1947) and the time of their appearance measures the moment when the activation wave passes under the electrode. This is usually in very close relationship to the posterior wall of the left auricle, because the distance between auricle and esophagus usually does not exceed a few millimetres. The theory of Lewis (1925) that the intrinsic deflections correspond to the time when activation passes the electrode has been attacked by various authors. Recent experimental findings, however, speak in favour of the opinion, that it is not inaccurate to use the intrinsicoid deflections in both osophageal and intracardiac leads as an indication of the time of arrival of the process of activation under the electrode (Groedel et al., 1948; Sodi-Pallares et al., 1950; Wilson et al., 1947).

We measure the interval from the beginning of the intrinsicoid deflection (i) to the QRS complex and call this distance $\mathrm{i}-\mathrm{R}$ interval. Normally this interval (it may also bring into correlation the $\mathrm{P}-\mathrm{R}$ interval in form of the quotient $\mathrm{P}-\mathrm{R} / \mathrm{i}-\mathrm{R}$ ) is of about the same length in all osophageal auricular leads (Deutsch et al., 1949; Wenger, 1947 and 1952). This speaks in favour of the assumption that conduction takes place normally in a transverse direction from right to left. From this we conclude, that normally - as it is also known from animal experiments (Lewis, 1925) - the activation reaches the left auricle, coming over from the right auricle, at various levels of the posterior wall at more or less the same time, If we sketch these facts in form of an atriodiagram, we get a more or less vertical curve; on the horizontal line of the diagram the $\mathrm{i}-\mathrm{R}$ intervals are recorded and in the vertical direction the distances of the œsophageal electrode from the diaphragm are shown (Fig. 1, lines $b$ and $d)$.

In cases of nodal rhythm or nodal ectopic beats it is a priori questionable if the retrograde stimulus is using the normal pathways that conduct the normal stimulus from the right auricle to the $\mathrm{A}-\mathrm{V}$ node, in the reversed direction. If this should be the case, the activation could reach the left auricle at its inferior part and continue its caudocranial course in the auricle, or it could use the same pathways from right to left as in sinus rhythm. In this case the $\mathrm{i}-\mathrm{R}$ intervals at various heights of the œsophageal electrocardiogram would be more or less equal and the atriodiagram would show a normal pattern. In the other case (of caudocranial conduction through the left auricle) the $i-R$ intervals would be registered earlier in deeper, and gradually later in higher, osophageal leads at auricular levels.

To establish this we investigated two cases of nodal rhythm and three cases of nodal ectopic beats by means of œsophageal electrocardiography.

\section{RESULTS}

Case 1. A man, age 31 years, with mitral and aortic valvular disease and subacute bacterial endocarditis. The cardiogram shows a regular rhythm, frequency 151 a minute. There are small $\mathrm{q}$ waves and upright 
QRS complexes in all three standard leads. The $T$ waves are diphasic $(-+)$; it seems that in the initial part of each $T$ wave a negative $P$ wave is hidden.

The osophageal leads show at $+4 \mathrm{~cm}(4 \mathrm{~cm}$. above the diaphragm) a $Q R$ pattern of $Q R S$ and an intrinsicoid deflection of the P wave, which falls 0.09 sec. after the beginning of the QRS complex. This intrinsicoid deflection starts at the isoelectric line. At $+5 \mathrm{~cm}$. the $R-i$ interval is $0.1 \mathrm{sec}$. It is $0.12 \mathrm{sec}$. at $+8 \mathrm{~cm}$. and $0.14 \mathrm{sec}$. at $+11 \mathrm{~cm}$. The osophageal $P$ waves have the form of an Rs at this level (Fig. 2). The atriodiagram is shown in Fig. 1, line a.

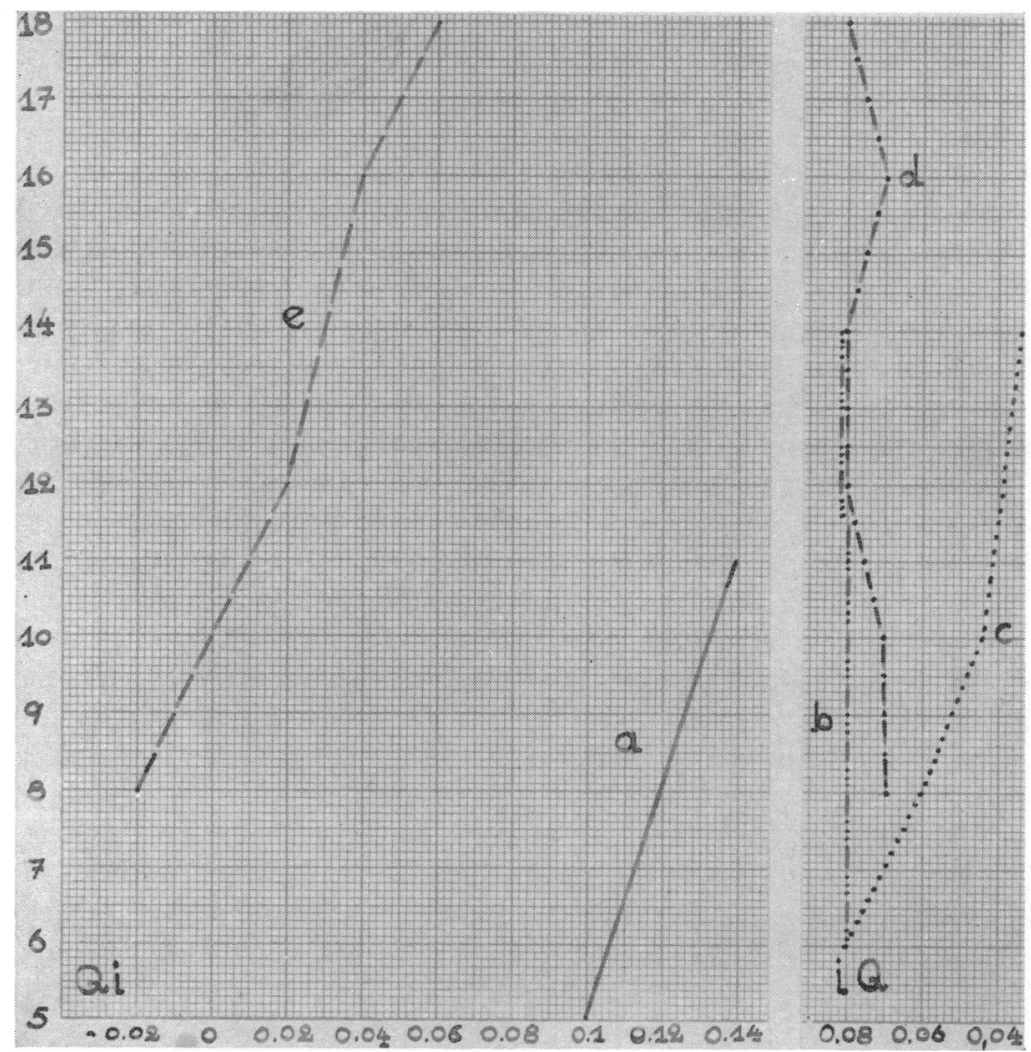

FIG. 1.-The $Q$ intervals are shown on the horizontal line, the heights of the osophageal electrode above the diaphragm are shown on the vertical line. Line $a$-Atriodiagram corresponds to the nodal rhythm of Case 1 (Fig. 2). Line $b$-Atriodiagram of the normal beats of Case 2 (Fig. 3). It is a straight, vertical line. Line c-Atriodiagram of the (probably nodal) ectopic beats of Case 2 (Fig. 3). The line is directed from the left below to the right above. Line $d$-Atriodiagram of the normal beats of Case 3 (Fig. 4). It is a more or less vertical line. Line $e$-Atriodiagram of the nodal ectopic beats of Case 3 (Fig. 4). The line is oblique from the left below to the right above.

Case 2. A lady, age 61 years, who was suffering from ischæmic heart disease. The cardiogram shows ectopic beats. Their P waves are low in I, diphasic in II and isoelectric in III, VR, VL, and VF. They are very flat in V1-V4, isoelectric in V5 and V6. The P-R interval is $0.16 \mathrm{sec}$. on the normal and 0.08 on the ectopic beats (Fig. 3). The osophageal leads show a normal atriodiagram concerning the normal beats (Fig. 1, line b). The $\mathrm{i}-\mathrm{R}$ distance is $0.08 \mathrm{sec}$. in all heights above the diaphragm, where intrinsicoid deflections are present. They show $\mathbf{R}-\mathbf{S}$ patterns of the $\mathbf{P}$ waves. The $\mathbf{i}-\mathbf{R}$ intervals of the ectopic beats are gradually decreasing from $+6 \mathrm{~cm}$. $(0.08 \mathrm{sec}$.) to $+14 \mathrm{~cm}$. $(0.04 \mathrm{sec}$.). The $P$ waves at the lower heights 


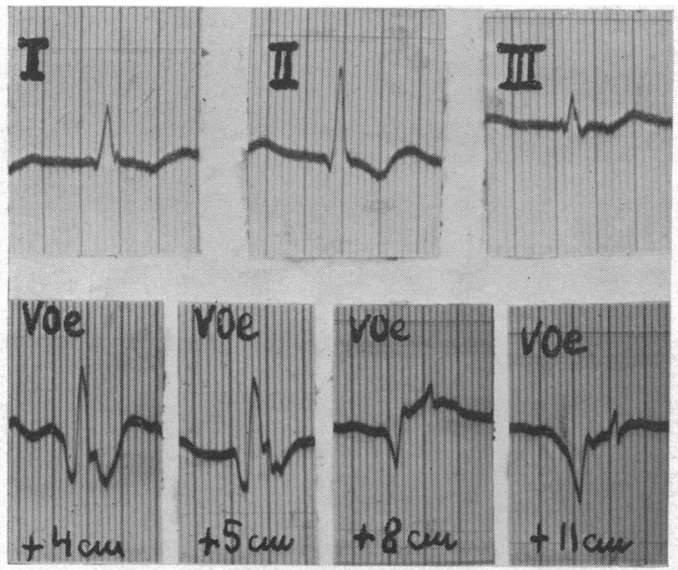

Fig. 2.-Nodal rhythm with inverted $P$ waves, which follow the QRS complexes and are imbedded in the ascending limb of the $T$ waves. The intrinsicoid deflections of œsophageal leads show a progressive retardation in a direction from below upwards. They are $0.09 \mathrm{sec}$. after the beginning of QRS $4 \mathrm{~cm}$. above the diaphragm $(+4 \mathrm{~cm}$.), $0.1 \mathrm{sec}$. at $+5 \mathrm{~cm} ., 0.12 \mathrm{sec}$. at $+8 \mathrm{~cm}$., and 0.14 sec. at $+11 \mathrm{~cm}$. (Fig. la). The atriodiagram (Figure 1a) shows a curve that is directed from left below to right above. Case 1 .

show only low initial positive deflections, whereas at higher levels they show R-S patterns. The respective atriodiagram is shown in Fig. 1, line c.

Case 3. A lady, age 45 years, with carcinoma of the breast. There is no significant pathological cardiac finding besides that of ectopic beats. In the cardiogram ectopic beats are registered, which do not show any $\mathbf{P}$ waves in the standard, unipolar extremity, or chest leads. The amplitude of the ectopic beats is markedly higher in leads II and III in comparison with the normal QRS complexes. The esophageal leads show negative QRS complexes in auricular levels. A more detailed evaluation of these leads shows that $8 \mathrm{~cm}$. above the diaphragm an intrinsicoid deflection is present $0.02 \mathrm{sec}$. before the beginning of QRS.



FIG. 3.-Ectopic beats with $P$ waves, which precede the $Q R S$ complexes at an interval of 0.08 sec. (P-R interval of normal beats $0.16 \mathrm{sec}$.). The ectopic $P$ waves are low in I, diphasic in II, and isoelectric in III. (Esophageal leads. - The normal beats show at all levels intervals of $0.08 \mathrm{sec}$. Therefore, the atriodiagrams show a straight, vertical line (Fig. 1b). The ectopic beats show a progressive shortening of the $i-R$ intervals, proportional to the increasing height of the electrode above the diaphragm. Therefore, the atriodiagram shows a curve, which has a direction from the left below to the right above (Fig. 1c). Case 2. 
At $+1 \mathrm{~cm}$. no intrinsicoid deflection is to be seen, as it coincides with the downstroke of the $Q$ wave. At $+2 \mathrm{~cm}$. an intrinsicoid deflection is again visible, which follows $0.02 \mathrm{sec}$. after the beginning of QRS. So it shows a gradual retardation until the height of $+18 \mathrm{~cm}$., where it is to be seen $0.06 \mathrm{sec}$. after the beginning of the $\mathrm{Q}$ wave (Fig. 4 and Fig. 1, line $\mathrm{d}$ for normal, line e for ectopic beats).

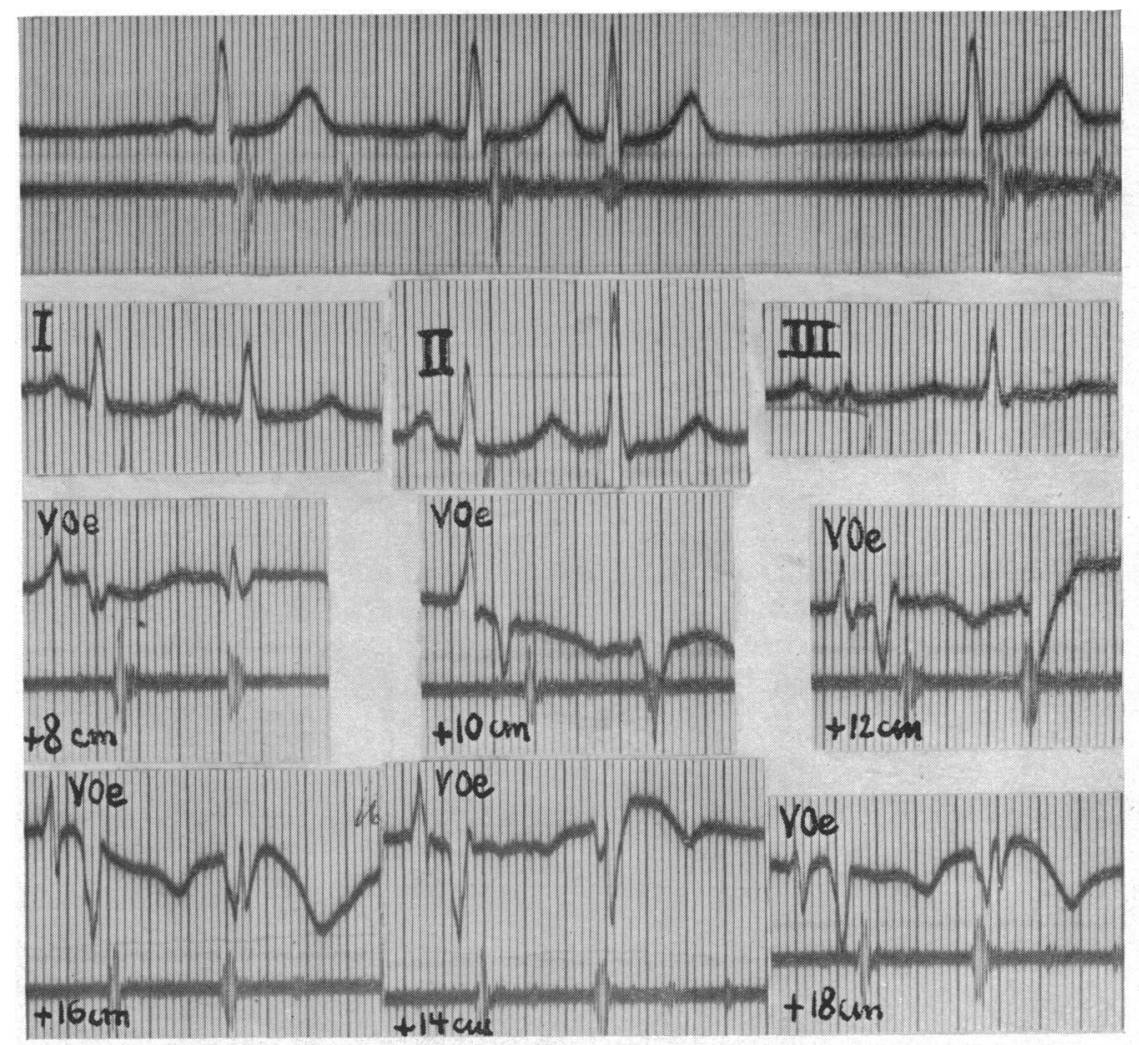

FIG. 4.-There are nodal ectopic beats, which do not show any $\mathbf{P}$ waves. In the œsophageal leads, the normal beats show a normal atriodiagram (Fig. 1d), which is more or less vertical. The $\mathbf{R}-\mathbf{i}$ intervals of the ectopic beats show intrinsicoid deflections, which precede the $Q$, at $8 \mathrm{~cm}$. above the diaphragm by $0.02 \mathrm{sec}$. At higher levels it shows a progressive retardation and $18 \mathrm{~cm}$. above the diaphragm the $\mathrm{R}-\mathrm{i}$ distance is $0.06 \mathrm{sec}$. The atriodiagram of the ectopic beats, therefore, shows an oblique curve, as in the previous cases (Fig. 1e). Case 3.

\section{Discussion}

Case 1 shows a nodal rhythm with negative $P$ waves, which follow after the QRS complexes (Fig. 2). The atriodiagram is represented by a curve, which passes upwards and to the right (Fig. 1a). This means, that at $4 \mathrm{~cm}$. above the diaphragm the activation reaches the electrode $0.09 \mathrm{sec}$. after the beginning of QRS, whereas this time interval increases gradually the higher up we record in the œsophagus. This corresponds to a spread of the activation wave along the posterior wall of the œsophagus in a caudocranial direction. Only a stimulus that arises in the A-V node can cause such a pattern. We have not seen this form of atriodiagram except in some cases of auricular flutter (1952). According to the classical concept the stimulus arises in the lower part of the A-V node in this case.

Case 2 shows ectopic beats with $P$ waves, which are preceding the QRS complexes by a shorter interval $(0.08 \mathrm{sec}$. as against $0.16 \mathrm{sec}$. in the normal beats). The $P$ waves are not inverted in any 
standard lead, but they are diphasic in lead II and isoelectric in lead III (Fig. 3). Also in this case the left atriodiagram shows a curve, which is going upwards and to the right (Fig. 1c). It remains questionable, if the ectopic beats arise in the A-V node or in the lowest part of one of the auricles. The second possibility has to be taken into consideration because the $P$ waves come before the QRS complexes and are not inverted in any standard lead. Also in this case the typical change of the pattern of $\mathrm{P}$ in œsophageal leads ( $\mathrm{rS}$ in lower, $\mathrm{RS}$ in higher leads) may be observed. Therefore, we conclude, that in Case 2 the ectopic beats arise in the superior part of the A-V node or perhaps in a very low part of one of the auricles.

In Case 3 no $P$ waves can be seen before or after the QRS complexes (Fig. 4). The œsophageal leads show that the $P$ waves are hidden in the QRS complexes. At the lowest auricular levels $(8 \mathrm{~cm}$. over the diaphragm) they are preceding the ventricular complexes at an interval of $0.02 \mathrm{sec}$. This does not cause the appearance of a visible $\mathbf{P}$ wave in any of the standard unipolar extremity or chest leads. The atriodiagram shows a normal pattern for the normal beats (Fig. 1d) and an oblique curve (as described in the previous cases) for the ectopic beats (Fig. 1e).

This appearance of auricular intrinsicoid deflections in œsophageal leads is evidence that the stimulus arises from the A-V node. According to the classical conception it would have to be assumed, that the stimulus has its origin at the middle region of the A-V node. The œsophageal cardiogram in such cases also allows one to differentiate between an A-V nodal rhythm with auricular asystole or auricular fibrillation and nodal rhythm with retrograde activation of the auricles, which occurs at the same time as the activation of the ventricles. In either case the $\mathbf{P}$ waves may be absent in the usual bipolar and unipolar leads.

\section{CONCLUSIONS}

In cases of nodal rhythm or nodal ectopic beats, œsophageal leads show a typical pattern. The intrinsicoid deflections of the $P$ waves may be registered relatively early (in comparison to the beginning of the QRS complexes) in low auricular levels, whereas they show a progressive retardation as the cardiogram is registered higher up in the œsophagus. This is in contrast to the normal relations. In cases of sinus rhythm the intrinsicoid deflections show more or less the same time relationship to the subsequent QRS complexes in œsophageal leads. This may be evaluated numerically by measurement of the $\mathrm{i}-\mathrm{R}$ intervals (interval from beginning of the rapid downstroke, (intrinsicoid deflection of $P$, to the beginning of the QRS complex). It also may be shown by " atriodiagrams," which show a more or less vertical curve in cases of sinus rhythm and an oblique curve (from the left below to the right upwards) in cases of nodal rhythm or nodal ectopic beats.

If the $P$ waves of the ectopic beats precede the QRS complexes and are not directed downwards in lead II and III, it might perhaps be possible that they arose from the lower part of one of the auricles. This might be so in Case 2, whereas Cases 1 and 3 show clear evidence of the nodal origin of the rhythm or of the ectopic beats.

When the retrograde activation of the auricles occurs simultaneously with the activation of the ventricles, so that no $P$ waves are seen in the usual leads, œsophageal leads may be important for the differential diagnosis between a nodal rhythm from the middle part of the A-V node and a nodal rhythm with auricular asystole or auricular fibrillation. It should be mentioned also, that a similar behaviour of the intrinsicoid deflections has been observed in some cases of auricular flutter.

\section{SUMMARY}

Esophageal leads are of diagnostic importance for the elucidation of $\mathrm{A}-\mathrm{V}$ nodal rhythms or nodal ectopic beats. The gradual delay of the intrinsicoid deflections of the auricular complexes corresponding to increasing heights of the electrode above the diaphragm may be shown clearly by "atriodiagrams." 


\section{REFERENCES}

Brown, W. H. (1936). Amer. Heart J., 12, 1.

Deutsch, E., Hofmann-Credner D., Wenger R. (1949). Ztschr. Kreislaufforsch., 38, 718.

Groedel, F. M., Borchardt, B. R. (1948). Direct Electrocardiography of the Human Heart and Intrathoracic Electrocardiography. New York.

Lewis, T. (1925). The Mechanism and Graphic Registration of the Heart Beat. London.

Neumann, M. Z. (1951). Terap. Arkh., 22, 34.

Schwartz, M. (1947). Northwest. Med., 46, 448.

Sodi-Pallares, D., Barbato, E., Delmar, S. (1950). Amer. Heart J., 39, 387.

Wenger, R. (1947). Ztschr. Inn. Med., 28, 490. (1950). Cardiol., 39, 243.

(1949/50). Cardiol., 15, 365.

Hofmann-Credner, D. (1952). Circulation, 26, 28153.

, - - Hörtnagl, W. (1950). Ztschr. Kreislaufforsch., 39, 653.

Wilson, F. N., Rosenbaum, F. F., Johnston, F. D. (1947). Advances in intern. Med. 2, 1. 